Article

\title{
Towards an Integrated Framework for SDGs: Ultimate and Enabling Goals for the Case of Energy
}

\author{
Måns Nilsson ${ }^{1, *}$, Paul Lucas ${ }^{2}$ and Tetsuro Yoshida ${ }^{3}$ \\ 1 Stockholm Environment Institute, Kräftriket 2B, Stockholm 10691, Sweden \\ 2 Netherlands Environmental Assessment Agency, P.O. Box 30314, The Hague 2500 GH, \\ The Netherlands; E-Mail: paul.lucas@pbl.nl \\ 3 Institute for Global Environmental Strategies, 2108-11 Kamiyamaguchi, Hayama, \\ Kanagawa 240-0115, Japan; E-Mail: t-yoshida@iges.or.jp \\ * Author to whom correspondence should be addressed; E-Mail: mans.nilsson@sei-international.org; \\ Tel.: +46-733-309-382; Fax: +46-8-674-7020.
}

Received: 19 August 2013; in revised form: 9 September 2013 / Accepted: 10 September 2013 / Published: 25 September 2013

\begin{abstract}
Discussions on how to define, design, and implement sustainable development goals (SDG) have taken center stage in the United Nations since the Rio+20 summit. Energy is one of the issues that enjoyed consensus, before and after Rio, as an important area for SDGs to address. Many proposals have been put forward on how SDGs should be formulated and what areas they should cover, but there have been few attempts to develop a generic integrated framework within which diverse areas can be accommodated and treated in a coherent way. The purpose of this paper is to develop such a framework for SDGs and to demonstrate its application by elaborating specific target areas for the energy sector. Based on a review and integration of global debates around SDG and energy, the framework puts human wellbeing at the center of the agenda, with the supporting resource base and global public goods forming additional tiers. A complementary set of enabling goals is suggested with four layers: capacity \& knowledge, governance \& institutions, public policy, and investment \& finance. An energy SDG is elaborated to illustrate the application of the framework. The illustrative SDG architecture for energy includes eight target areas: basic energy access, energy for economic development, sufficiency, renewable supply, efficiency, infrastructure, greenhouse gas emissions and security. These target areas are relevant for energy for all countries, but depending on national circumstances such as levels of development, the relative emphasis will be different between countries, and over time.
\end{abstract}


Keywords: sustainable development goals; pathways; energy; security; access; equity; poverty; growth; climate

\section{Introduction}

At the United Nations Conference on Sustainable Development (Rio+20), in June 2012, a process was initiated to formulate a set of sustainable development goals (SDGs) for pursuing focused and coherent action on sustainable development [1]. Since Rio+20, discussions on how to define, design and implement SDGs have taken center stage in the United Nations. A multitude of interpretations have been put forward of how SDGs should be formulated and operationalized and what areas they should cover, but there have been very few attempts to develop a generic framework within which diverse areas can be accommodated (see below).

The objective of the paper is to develop a basic SDG framework for identifying relevant targets for specific goal areas. The framework should be simple and intuitive but also applicable across a wide range of development sectors, such as food, health, education, housing, or water and sanitation, as well as capturing a complex global and multilevel policy context where both universality and context-specificity (in both time and space) is required.

The paper illustrates the framework's application with an energy SDG. Although the list of potential issues to be included in the SDGs is still long, and research papers should not be selecting goals on behalf of the policy makers, energy is one of the issues that enjoys consensus as a priority area both within and outside the UN system. The Rio+20 outcome document recognized the critical role that energy plays in the development process. The Secretary-General's Sustainable Energy for All initiative (SE4All) has established a first set of targets that enjoys widespread agreement and can be used as a point of departure. Furthermore, energy is part of many recent proposals on the post-2015 development agenda and the SDGs, either addressed by an individual goal or integrated in specific targets, and can therefore serve as a relevant illustration.

As the policy processes have proceeded, global thinking on SDGs appears to have converged on the notion that they must connect poverty alleviation, human wellbeing, and environmental protection in new and more integrated ways [2-5]. However, the actual articulation of goal areas and targets, or even the basic principles that should underpin them, has proven politically challenging. This paper does not aspire to pre-empt the multilateral process on what SDGs should look like. Researchers should refrain from articulating political goals-this must be an outcome of the international political process. However, we should make available the theoretical and empirical knowledge base necessary to make informed choices about goals, including goal architecture in general, as well as specific sustainable development challenges, and ways in which they can be represented in a coherent way in policy frameworks. With this in mind, we hope to contribute to both the policy discourse and the academic understanding of global development goals.

Based on a review and integration of mostly separate global policy and research debates on development goals and on energy, we propose a simple three-tiered framework for the SDGs, following a "people first" approach that puts human wellbeing at the center of the development agenda [6]. 
The framework recognizes that attaining human wellbeing in the long term is dependent on a development context where resources and capital (both manmade and natural) are safeguarded and global public goods (including environmental ones) need to be resolved. Thus far, it draws inspiration from the early deliberations of the High-level panel in 2012 where a three-tiered approach was discussed; building individual capabilities, expanding national opportunities, and managing global risks [6]. It further elaborates on the notion and need for enabling conditions, and articulates four layers of enabling goals.

Developing an SDG architecture is ultimately a political decision that must draw upon diverse disciplines and perspectives. This paper combines insights from multiple disciplines, including economics, development theory, philosophy, and social and natural sciences. It should be recognized that the principles and priorities presented with such a starting point are not free from values or assumptions. They could be claimed to fall in the mainstream of 20th Century philosophical liberalism in assuming for instance that all people value their personal freedom and wellbeing, and that public interventions anchored in a democratic liberal society are needed to uphold basic human rights. Insofar as such principles are in accordance with the foundations of the multilateral system and international law, they provide a legitimate basis upon which to construct SDGs.

The paper proceeds as follows. Section 2 introduces and discusses some key considerations for the SDGs and positions them in a framework with three tiers of ultimate goals and four layers of enabling goals. Section 3 will introduce the key development challenges associated with energy and how they can be addressed in a basic architecture of SDGs. Section 4 presents main categories and examples of enabling goals. Section 5 discusses how a pathways approach can be used to assess the coherence of the agenda in relation to other goal areas. Section 6, finally, presents conclusions and some implications for the broader SDG agenda.

\section{Key Considerations for SDGs: A Three-Tiered Framework}

Over the last year, a plethora of UN bodies, policy analysts, advocacy organizations, and research groups has presented suggestions and approaches to a post-2015 development agenda and the SDGs. All proposals put ending poverty at the core of their development agenda by including goals on poverty, education, and health, but also on issues such as ending hunger and ensuring full access to modern energy, safe drinking water, and improved sanitation. Furthermore, many proposals have been strongly influenced by the environmental sustainability research community, in particular the widely popular concept of planetary boundaries, and the need to respond to a global environmental crisis as a basis for firm action $[7,8]$ by addressing issues like sustainable agriculture, climate change, deforestation, freshwater withdrawal, ecosystem services, and natural resource management. However, the ways in which proposals combine poverty eradication with environmental sustainability differ widely. Some proposals follow the same logic as the Millennium Development Goals (MDGs), but extend the timeline for achieving the goals or add new goals, including on environmental sustainability [7], whereas others present more comprehensive approaches that integrate the three sustainability domains in a single goal [3,9], or specifically address development within natural resource limits $[10,11]$.

However, as indicated by the lack of substantive progress in both the climate change convention and the sustainable development summits, such as Rio+20, it can be questioned whether a globally 
embraced environmental sustainability norm is sufficiently institutionalized to induce action as the core objective of the SDG agenda [12]. Policy makers tasked with negotiating and implementing development goals and strategies are rarely in a position to give global environmental issues a principled priority. Instead, their main concerns are usually related to areas such as the political stability of their regime, economic development or growth, and the wellbeing and prosperity of their citizens. Whereas strong sustainability notions such as planetary boundaries remain deeply contested in the policy sphere, there is a little disagreement over the need to stimulate development and secure livelihoods.

This paper presents how the human wellbeing agenda can form a tractable core notion for formulating SDGs, while integrating environmental and economic aspects as critical conditions in additional tiers within this agenda. This "tiering" of priorities has been suggested in policy papers $[5,6]$ and in stakeholder contributions [11], and resonates with both the need for nesting development agendas $[4,8,11,13]$, and using a multilevel approach to a global development agenda.

\subsection{Tier 1: Pursuing Human Wellbeing}

Over the last decade, thanks to rapid economic development in many parts of the world, aggregate human wellbeing has undoubtedly increased. The opening of markets and trade has generated wealth and growing incomes worldwide, and has contributed to lifting hundreds of millions out of poverty [14]. In many contexts, MDGs have played a role by providing a common development agenda globally and focusing attention on critical aspects of poverty reduction. However, economic policy often pursues objectives for the aggregate economic wellbeing of a society, with the afterthought that if aggregate wellbeing increases, "winners can compensate losers" and everyone will be better off. However, arguably this latter part tends be forgotten in implementation, as evidenced by growing inequalities in higher-income countries and in rapidly growing economies [15]. Moral philosophers, such as Gewirth [16], have shown that, contrary to the economic utilitarian view, the end objective cannot be the aggregate wellbeing but the wellbeing and freedom of each individual, or more exactly the opportunity for each individual to pursue wellbeing and freedom. Gewirth states, "Act in accord with the generic rights of your recipients as well as of yourself" ([16], p. 135). Indeed, in this simple statement lies a foundation both for the sustainable development principle as articulated famously in the Brundtland report from 1987 (“...development that meets the needs of the present without compromising the ability of future generations to meet their own needs...."). That people everywhere share the same basic rights to wellbeing has strong foundations in international law and in many national constitutions. Indeed, also economists have been concerned that one person's wellbeing cannot be weighed against another's [17].

Most observers today consider rising inequalities a both socially unstable and ethically unacceptable situation. However, this is not only an ethical consideration but can be argued from an economic efficiency perspective as well. Recent analyses have shown that the increasing inequality that has resulted from global economic change has become not only a social, political, and ethical problem but is also an economic problem. Current inequalities within countries reflect market and policy failures and constitute a growing barrier to growth and development [15].

At the core of the development agenda, and also in current proposals, is thus the fulfilment of rights for the wellbeing of all people. The report of the high-level panel on the post-2015 development 
agenda addressed five big transformative shifts in international cooperation and policy making, with the first being: 'leave no one behind' [5]. Where the MDGs focused on halving poverty, tending to target those people just below the poverty line, this shift includes goals and targets that address all groups in society- referred to as "universality" in the UN discussions.

Wellbeing is a complex concept and cannot be comprehensively discussed in this paper. Its complexity creates challenges for using it as an SDG foundation but it has two major advantages. First, it enables us to find a focus in a broad and integrated approach. Second, wellbeing readily lends itself to be applied to a universal agenda. Dasgupta suggests that wellbeing should be classified as either constituents (health, happiness, freedom) or determinants (access to food, nutrition, water, shelter, knowledge) [18]. Within philosophy, a more nested perspective seems to prevail, with wellbeing being economic or material, but also involving social inclusion, dignity, respect, and human capabilities towards self-fulfillment [19]. Sen prefers to talk about freedoms, constituted by an essentially similar set of factors; influenced by economic opportunities (e.g., to participate in trade and production), political liberty (free speech and elections), social empowerment and conditions such as good health and education [20].

Thus, components of wellbeing overlap, cannot be easily aggregated and need to be considered in their own right. They include access to important resources and services at the individual level to cover our basic needs, security, dignified livelihoods and basic access to resources such as food, water, sanitation, energy, health, housing, safety, and education. A development agenda based on these components necessarily also includes opportunities to participate in economic activities, social inclusion, and empowerment. These constituents could together form the core of a generic SDG framework. In this paper, we will go through one of them in more detail.

Conversely, ever-increasing consumption of basic goods does not lead to ever-increasing levels of wellbeing or freedom. At a certain level of "saturation", returns in terms of human development start leveling off [21]. In the case of energy, for example, the correlation between the Human Development Index and per capita energy use levels off at $c a .3000$ kgoe per year (This is below the average European consumption and less than half of the US consumption) [22]. There is actually some convergence from economics, philosophy, religion, and psychology on this conclusion. From an economic efficiency perspective, the argument has also been made that rich societies consume too much (due to market failures in the factor prices) and that there is a need for corrective public policy [23]. Many of the large religions call into the question Western consumerism in a profound way, and psychologists have even dubbed it "pathology" [24]. From a natural resources perspective (including pollution and degradation), increasing wellbeing and, related, increasing consumption, requires reduced resource use from those already much better off. Such decoupling could be accomplished through increased resource efficiency, including the use of alternative resources (see also Section 2.2 on the resource base), but also through reduced consumption of resource intensive goods and services.

In summary, putting wellbeing at the center of a universal SDG framework rests on two basic ideas. First, in poor societies, lack of access to basic goods and services that would enable and create opportunities for economic and social development is a well-known barrier to wellbeing. Second, ever-increasing levels of consumption of goods and services amongst high-consumption groups do not 
lead to greater levels of wellbeing or human development. In fact, vast inequities, be it in income and economic opportunity or in use of services, are, in themselves, a barrier to wellbeing and development.

\subsection{Tier 2: Developing the Resource Base}

Any undergraduate economics textbook starts with the point that economics is the study of how society allocates scarce resources to competing uses. Indeed, "scarcity of means to satisfy ends of varying importance is an almost ubiquitous condition of human existence" ([25], p. 15). This means that the pursuit of wellbeing and freedom is conditioned and constrained by the quantities and qualities of the resource base that surrounds us. This is also recognized by the well-established "sustainable livelihoods" framework, where livelihood outcomes are based on the resources (assets or capitals) that people have access to [26]. The second tier of goals deals with this resource base. A resource perspective allows us to get a handle on the multiple bases upon which people and societies build wellbeing and freedom. The World Bank has for many years worked on the concept of capital and assets, where not only conventional man-made capital but also social capital and natural capital, are accounted for to examine how the full capital bases at the national level are changing over time. As suggested by some indicators, such as "genuine savings" or "adjusted net savings", preserving the resources and the capital basis for future generations is a key sustainable development consideration [27]. This consideration of a sustainable development of the underlying resource base is the major difference from indicators such as included in the Millennium Development Goals (MDGs) and Commission for Sustainable Development (CSD) indicators which list targets and indicators, but do not show whether a country is developing sustainably or not.

By contrast, "adjusted net savings" measures a more comprehensive rate of savings in an economy after taking into account both investments and depletions in the capital base, including in human capital, economic capital, natural capital, and damages caused by pollution. Negative adjusted net saving for a country means that total wealth is in decline. Indeed, these measurements have shown that many countries have failed to maintain not only natural capital but also the man-made resource base over the last decade, including energy and transport infrastructure, but also health and education systems. It should be noted that the national scale is not necessarily the most adequate level of governance for all kind of resources. Many of them rely on coordination at subnational or international levels (see also Section 2.3). Still, many of the resource bases upon which development depends are maintained and drawn upon at a national scale.

Resource efficiency is central to this tier. In the inevitable context of scarce resources, the quest for resource efficiency and productivity takes on a special position in both private and public spheres. A number of industrialized and emerging economies use large amounts of raw materials like oil, iron ore, coal, rare earth metals and woods, causing deforestation, biodiversity degradation, air, water, soil pollution, and desertification in the exporting, often, developing countries. As it is not realistic to substantially reduce the size of the world population or material welfare levels, there are not many choices left but to increase resource efficiency in production and consumption of goods and services to enable a long term development and sustainable use of the resource base.

There is a long-standing critique against these economic representations of different resources and capital bases using standard national accounting approaches. One issue is that they are based on the 
assumption that all capitals can be substituted, which is certainly not always true. However, natural capital and services tend to be treated as free and valueless by policy makers when not monetized. Furthermore, all resources are interconnected. Indeed, resource use and its effects, ripple through economic systems and the environment.

In summary, how the pursuit of human wellbeing connects to the surrounding resource base is essential to the development agenda and should be included in an SDG framework, including the development and sustainable exploitation of the natural resource base, resource efficiency enhancement, and development and provisioning of man-made resources such as infrastructure.

\subsection{Tier 3: Managing Global Public Goods}

The third tier concerns functions in the global society that require conscious coordination and action at the international level. The theory of global public goods concerns the provisioning of benefits that do not have exclusive ownership rights and that are non-rival in use (one person's consumption does not affect another person's consumption) [28]. Not all public goods manifest themselves at the global scale, but most of them need to be managed through coordination and cooperation at the international level. These issues, if not managed properly, will constrain human development and use of the resource base, and as a result impede human and economic development at the core [4].

Certain aspects of the environment and use of natural resources are classical public goods, such as the climate or the ozone layer, whereas others are private goods. Over the last decade the specific public goods issues of the environment have increasingly become manifest at the global scale. This is a result of both the vast expansion of the human population and the simultaneous expansion of human economic activity. As a result, analysts have suggested that Earth has entered a new geological era called the Anthropocene [29]. In this era, the stability of Earth's natural systems, including a stable climate, oceans, and land and water systems, are dependent on human action (or inaction), as much as human development and prosperity depends on the functioning of these systems.

Global public goods are however not confined to environmental concerns. Other areas include the stability and functioning of international commodity markets, the international financial system, and global security. On the latter issue, the term "collective security" is a principle of the United Nations, in which each state in the system accepts that the security of one is the concern of all. By employing a system of collective security, the UN hopes to dissuade any member state from acting in a manner likely to threaten peace, thereby avoiding conflict. Although this concept is developed from "hard" security concerns, it applies equally to security in a broader sense, including energy security and food security.

In summary, the management of global public goods such as Earth systems, markets, and international security is of central importance to the pursuit of human wellbeing and the broader development agenda and needs a representation in the SDGs.

\subsection{Enabling Goals}

A fundamental premise of both liberal democratic states and many of the authoritarian states today and in history (as well as in many religions), is the obligation to help those that are not in a position to help themselves to pursue their basic needs. This is the basis for a "supportive state", which is needed to promote equality in the right and ability of people to pursue wellbeing and freedom, where the 
source of this ability is institutional. However, the state does not operate in isolation. Underpinning it we find social and governance structures and human beings with agency. The state's policies will ultimately be implemented (or not) via decisions, investments and actions in civil society. Reflecting this broader notion of governance, a broader set of enabling goals is warranted [30].

Our proposition is that four nested layers need to be included in an SDG framework. (1) At the most fundamental level this is about building human capacity, through the development and transmission of knowledge; (2) Building on this capacity, societies must ensure that governance and institutional frameworks are set in place so that people are empowered to draw upon those capacities in the pursuit of their wellbeing and freedom; (3) This institutional basis provides the source of agency, power and legitimacy for the "supportive state" which promotes the attainment of goals through public coordination and interventions through public policies; and (4) These policies and institutions in turn will enable and direct efforts of implementation, and in particular the investments needed in different development sectors, and the financing arrangements for these investments. Many of these enabling goals are sometimes referred to as "means of implementation" within the international cooperation discourse.

\subsection{A Generic SDG Framework}

Combining these arguments and concepts a conceptually coherent SDG framework can be derived. Figure 1 presents a simple model outlining the three tiers of ultimate goals, representing the actual end-points of the post 2015/SDG framework, followed by four layers of enabling goals, representing areas of action and intervention by different actors.

Figure 1. SDG framework: three tiers of ultimate goals and four layers of enabling goals.

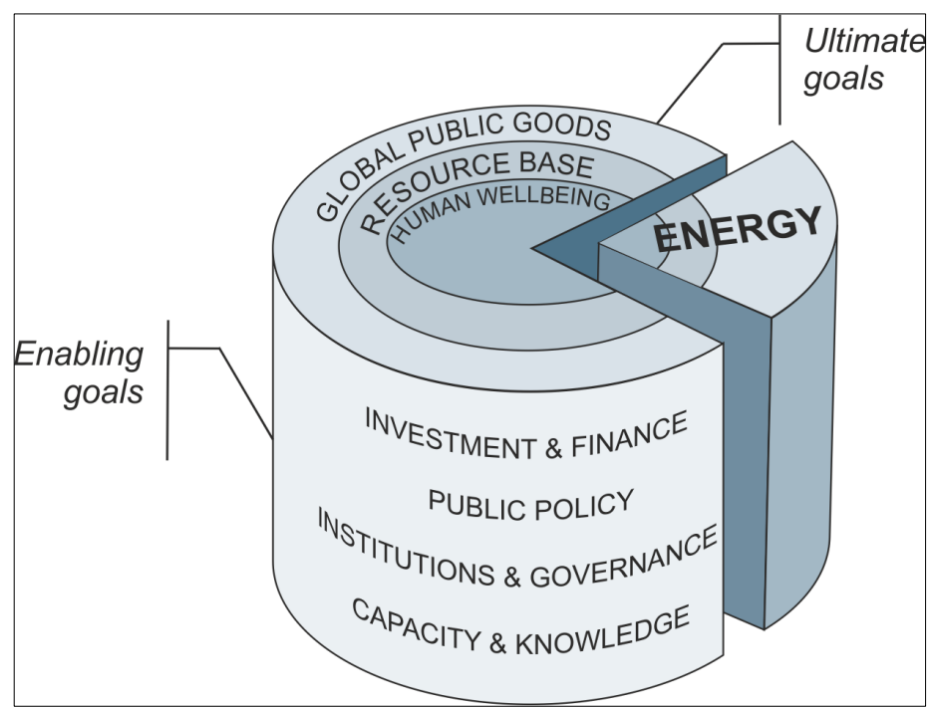

The "slice" is a representation of the main development goals for each issue and the means and measures required to achieve them. This basic structure is universally applicable, not only for the energy issue as we will illustrate in the next section, but indeed for all potential post 2015 goal areas, be they education, health, water and sanitation, food, or housing. These topics are all considered in the political process to be "slices" in the SDG framework, and they can all be represented and articulated in terms of the three tiers and four layers. Indeed, also social sectors such as education and health are 
amenable to these generic categories, and have strong dimensions of both global public goods (e.g., the containment of disease and vaccination programs) and required resource bases (e.g., hospitals and school infrastructures).

The tiering and layering enables us to keep the number of "headline" SDGs to a manageable number, while also allowing the unpacking of specific sets of target areas for each goal, allowing sufficient granularity for being able to manage and establish means of implementation. This also enables the combination of universal goals (relevant for all countries), and country and context-specific targets.

\section{Energy as a Worked Example of a Sustainable Development Goal}

Energy is essential for economic development and for human wellbeing. However, the energy sector faces major challenges across the social, environmental and economic dimensions of development: lack of basic access for the poor, lack of capacity for productive uses in many areas, adverse impacts of climate change, energy-intensive lifestyles and inefficiency, health impacts from air pollution, and political tension due to insecurity of supply [31]. As an expected three billion people in developing and emerging economies will lift themselves out of poverty and enter middle-income [13], they will also require energy services at much higher levels than today. The energy demand is projected to grow globally by a factor of three over the 21 st Century, a challenge that must be met in ways that do not deplete our resource base, destroy the climate, or cause political tension [31]. This section identifies the key dimensions of the energy development challenge that needs to be addressed in the context the SDG framework. It builds on the ground-work of UN's SE4All initiative and its action agenda [32], but complements this agenda with key insights from recent international assessments [33-36]. SE4All provides an excellent basis but has chosen a simplified goal architecture where the focus is on developing countries. Most recent SDG proposals make reference to SE4ALL and include the three principal objectives $[4,5,8,13]$ : to ensure universal access to modern energy services, to double the global rate of improvement in energy efficiency, and to double the share of renewable energy in the global energy system (all by 2030). However, while some proposals even add one or two extra targets, none provide a more comprehensive view of energy development challenges articulated in the international assessments.

Although a comprehensive view provides for a complex set of target areas, a simple qualitative headline goal can still be formulated, such as the High-level Panel's suggestion "Secure Sustainable Energy", which can then be unpacked in the framework's tiers and layers. The three principal objectives of SE4All (relating to basic access, renewables, and efficiency) are represented as target areas in the first and second tiers, while additional target areas are articulated in all three tiers to represent the main universal energy challenges at different scales (see Figure 4).

\subsection{A: Pursuing Human Wellbeing}

At the core of the framework are the fulfilment of human need and rights for the wellbeing of all people. This includes access to important resources and services at the individual and household level (e.g., health, water, sanitation, energy), but also social aspects such as human security, social inclusion, and dignity. In the case of energy, this goal area addresses the availability of energy services to fulfill human needs and advance wellbeing. 


\subsubsection{Target Area A1: Basic Energy Access}

Modern cooking appliances and fuels, and distributed electricity access, are the two major issues within basic access to clean and affordable energy services. These are well articulated in SE4All. Taking improved human wellbeing, including equitable prosperity and opportunity, as a centerpiece in the development agenda, a starting point is that all human beings share similar needs, wishes and basic aspirations. We need to cover our basic needs, including security, dignified livelihoods, and basic access to resources such as food, water and energy. This concern corresponds directly to the need to ensure universal access to modern energy to eradicate poverty. For those 2.7 billion people who rely on polluting and inefficient stoves and fuels for cooking, and the 1.3 billion people who currently lack access to electricity, and the other billion people who have power only intermittently, lack of energy is a major barrier to development [33].

Indeed, although energy was not considered an explicit goal in the MDG framework, it is clear that energy is a key enabler for several of the MDGs. Modern energy contributes to eradicating extreme poverty and hunger (MDG 1) through powering pumps for drinking water as well as farm machinery and irrigation to improve agricultural yields. It contributes to universal education (MDG 2) through lighting to do homework, access to ICT, and freeing up time from fuel gathering, water fetching and cooking to do school work. Modern energy in particular empowers women (MDG 3) by reducing their burdens and stresses, and through street lighting it can improve safety and enable women to attend school or community activities after dark. [37,38] Modern energy for cooking reduces risks of respiratory illness from indoor air pollution and allows households to more easily boil water. It also supports the functioning of health clinics and hospitals (MDGs 4, 5, and 6). Recent estimates point to almost four million premature deaths annually from household air pollution caused by traditional cooking fuels, with a disproportionate share for children under five [39]. Efforts for basic access should not be compromised by efforts to mitigate climate change (MDG 7). Improved basic access to clean energy will have negligible climate impacts and could improve household and local air quality significantly [40,41]. Targets can be related to a number of issues within basic energy access. SE4All's action framework outlines modern cooking, distributed electricity generation (off-grid, mini- and micro-grid) and grid extension as key areas. Percentages of national populations, gaining electricity access, are a common target in use today. Importantly, however, targets should be related to the quality (reliability) and actual use of the energy service rather than just the dissemination of the technology $[42,43]$. Analysts have taken an interest in understanding what levels of energy are needed for human needs. Goldemberg et al. estimated that we could attain "basic needs and much more for one kilowatt per capita" primary energy [44]. Decades later, we understand that what constitutes human wellbeing is always in flux, and the relationship to energy use, is a dynamic and changing one [45]. However, minimum standards can be set for lighting, and for modern fuel use. Lastly, in addition, impacts can be targeted, such as particulate matter emissions from traditional solid fuel use, or number of deaths or illnesses due to in-door air pollution. 


\subsubsection{Target Area A2: Energy for Economic Development}

In addition to basic access, targets for productive uses should be pursued. Beyond basic access at the household level, energy is also a precondition for economic development, and a basis for almost all economic activities. Furthermore, as poor communities rise from poverty, they also want to enjoy the benefits of modern society and the opportunities that come with it. Over time, as the poor get richer, a universal agenda must reflect this transition. Acknowledging that this requires a higher level of energy use and power supply capacity than the household-related energy, the Secretary-General's Advisory Group on Energy and Climate Change suggested that energy access must be addressed both in terms of "basic human needs" and "productive uses" [43]. Productive uses have been defined as "the application of energy derived mainly from renewable resources to create goods and/or services either directly or indirectly for the production of income or value" [46]. The productive use term has suffered from a narrow interpretation focusing on motive power such as engines and pumps. A broader interpretation of value and income should be applied, including activity in agriculture, industries, retail and services, and public sector uses such as health clinics, water supply and sanitation, and schools. These are all economic uses that go well beyond the typically low demand profiles of households. The energy requirements for economic uses are likely to change over time, as sectors change and economies reach new levels of income. Recent scenario analysis by the Stockholm Environment Institute (SEI) and partners shows the differences between pursuing a development agenda based on basic energy access and a "shared development agenda" that also entails productive uses for a development trajectory towards a middle income country status by 2050 [36] (see Figure 2).

Figure 2. Energy demand in Western Africa, middle-income trajectory versus basic energy access.

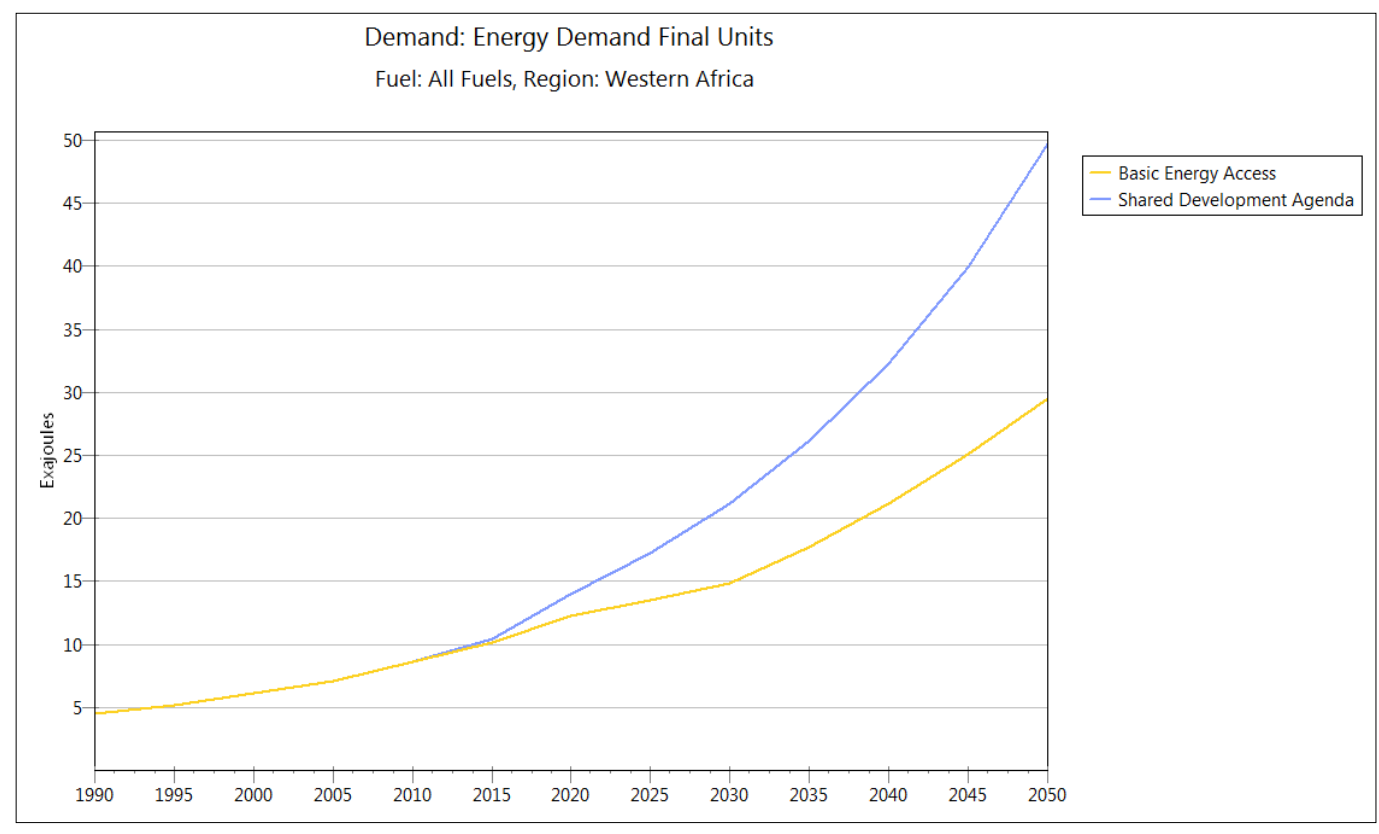

Estimates of what would be meaningful quantitative targets for energy for economic development will be highly context-dependent (for example on what economic activities are possible to pursue) and 
further measurements for what levels are required for "productive uses" need to be developed bottom-up, taking into account different socio-economic conditions and different sector needs.

\subsubsection{Target Area A3: Energy Sufficiency}

As argued above, energy-intensive lifestyles are a major driver of growth in energy use, but human wellbeing does not seem to increase alongside ever increasing energy uses [47]. Although there is very limited correlation between the level of wellbeing and the level of energy consumption beyond a certain point, people start consuming more energy as they become wealthier. This is evident from the comparison of data on per capita energy consumption of high-income countries, middle-income countries, and the least developed countries (see Figure 3). In view of scarce energy resources and their externalities, the promotion of energy conservation in rich societies is an essential component of the energy transformation. Unless we can provide all the required energy from renewable sources, it is critical to consider energy consumption, both in terms of carbon emissions and in terms of energy resource depletion overall. It has been suggested that 'If everyone in the world used oil at the same rate as the average Saudi, Singaporean, or U.S. resident, the world's proven oil reserves would be used up in less than 10 years' [48]. Thus, high-income consumer groups not only need to improve energy efficiency by using the best available technologies, but also consider their overall energy consumption in light of its contribution to overall wellbeing [49]. This agenda may be controversial, as some perceive reducing very high levels of consumption as a compromise of lifestyle. Steinberger and Roberts [50] investigated the relationship between human needs and energy for several indicators of human development: life expectancy, literacy, income, and the Human Development Index. They found that increasing energy use past a moderate level does not necessarily contribute to higher living standards.

Figure 3. Per Capita Energy Use (kg of oil equivalent).

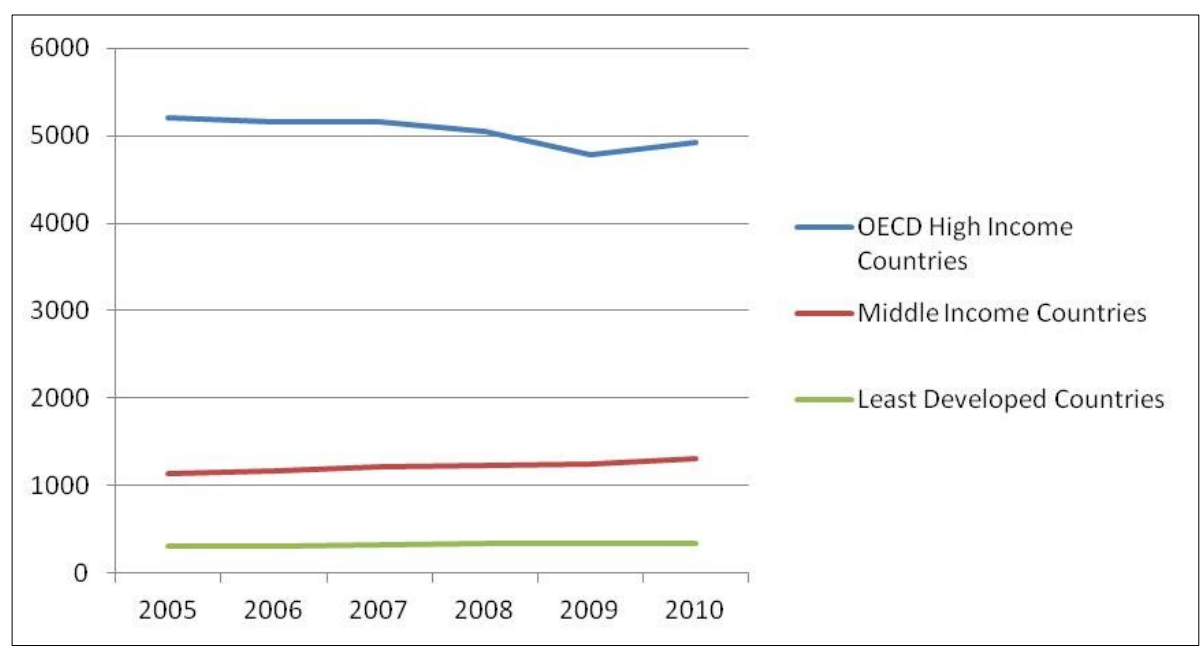

Source: World Development Indicators.

One way to deal with this is to explore conservation and savings targets. SE4All does not propose a goal for energy conservation, possibly out of a concern for alienating certain political groups. However, if SDGs are to be universal and applicable to developed countries, energy conservation is an 
integral piece of the puzzle [36]. In fact, conservation is already a common feature of energy policy in developed countries and need not be as controversial as sometimes assumed, if applied to groups that exceed a certain threshold of per capita energy use. Furthermore, also emerging economies such as China are today officially emphasizing energy conservation.

Meaningful targets must be developed according to context-considering how for example household needs and transportation distances vary from place to place. The guiding question for this target area can be: what is the energy service requirement for an efficient, modern lifestyle in different regions? Countries could establish targets for per capita energy and electricity consumption, taking into account proven potentials for efficiency improvements for household use. As for the other firsttier target areas, sufficiency target are likely to be changing over time, taking into account for example efficiency improvements (treated in tier 2) and lifestyle changes.

\subsection{Resource Base}

The second tier concerns the resources that societies draw upon to advance and develop the services and resources needed in tier one. In the context of energy, the natural resource base is a very direct input to the sector and it is well understood that depletions in this capital stock has immediate repercussions on both national security and the global market. Increasing attention has been given in later years also to the produced capital/resource base, i.e., the energy infrastructure (in particular power transmission and distribution), which has been depleted in many high-income countries over the last decades. As for first-tier target areas, for all these areas in the second tier, specific target levels are likely to change over time, in particular due to technological change.

\subsubsection{Target Area B1: Renewable Energy Supply}

A significant scaling up of renewable sources of energy is widely agreed as critical for the energy sector, contributing both to mitigating climate change and air pollution, and enhancing energy security through reduced import dependencies and diversified supplies. Renewables currently contribute around $17 \%$ of world total primary energy use, predominantly from traditional biomass and hydropower [51]. The renewable energy goal of SE4All is a doubling of the share of renewable energy in the global energy mix by 2030 to approximately $30 \%$. This target is in line with the first steps in stringent climate mitigation scenario studies [52,53] and could kick-start the energy system transformation by stimulating technology development. Scenario studies show that renewables such as photovoltaics and wind can play a major role in the power sector, while bioenergy is by far the most important mitigation option for non-electric energy production in transport, heating, and industry [54]. Furthermore, bioenergy in the power sector in combination with carbon capture and storage can drive negative emissions, allowing the postponement of stringent climate effort [55].

However, rapid expansion of renewable energy use must be careful planned and assessed. Major controversies have arisen around bioenergy on the competition over land and water with food production and biodiversity [56]. Bioenergy production is also associated with considerable greenhouse gas emissions, including from nitrogen fertilizers and fuel, but also from direct and indirect land-use change [57]. Furthermore, hydropower controversies revolve around biodiversity loss, resettlements and loss of land and natural rivers. Estimates of sustainable resource potential must be a basis for 
development strategies and specific targets at the regional, national, or local scale, taking into account food security trade-offs, as well as issues such as land degradation, human settlements, water scarcity and biodiversity [58]. The sustainable global potential for bioenergy production in 2050 has been estimated to around 50-150 EJ. Higher potentials require assumptions about higher agricultural yields, shifting dietary patterns to low meat consumption, and lower population growth [59].

Targets can be set as specific levels of capacity expansion or share of total energy use of renewable energy as is currently done in the European Union. The target cannot be applied uniformly. For instance, a $30 \%$ renewable share can be too ambitious for some countries but already achieved for others. Countries like Iceland and Paraguay have already achieved 100\% renewable share of electricity but they have abundant geothermal and hydro power endowments that most countries do not have. Furthermore, the portfolio of renewables is subject to potentials and relative prices at the national level. For example, bio-energy is likely to play a more prominent role in Latin America and Sub-Saharan Africa, solar energy in the Middle East and North Africa, and wind in Europe and the United States [52]. For measuring and monitoring targets, there is a wealth of data sources compiling progress measurements already today, including IEA, IRENA, REN21, and Bloomberg Energy Finance. In principle, region, country, and community specific renewable energy targets should be set taking into account sustainable resource potentials and national capacities, while a global target should set the overall global trend and encourage efforts at multiple levels.

\subsubsection{Target Area B2: Energy Infrastructure}

Infrastructures for power generation, transmission and distribution remain a critical gap in the development resource base in many societies around the world. In addition, poor transport infrastructures are currently a major barrier to development, including in all economic sectors such as agriculture and tourism. In rich countries, infrastructures for electricity and gas are aging as investments in maintenance have been deprioritized as a result of short-termism in management and lack of finance. New and in many cases much higher demand profiles as well as integration of much higher shares of renewable energy will require changes in these infrastructures, including implementation of smart grid solutions for flexible and intelligent operation of power systems. Expanding and upgrading to modern and efficient infrastructures for electricity is therefore a key development priority for countries at all levels of development.

Targets can be established for setting up transmission capacity at national and regional (interconnection) level, gas pipelines, transport infrastructure expansion, implementation of smart grid solutions, distribution systems to unconnected areas, storage capacities, and balancing systems. Many of these targets will be qualitative and difficult to measure. It can therefore be useful to focus target measurement on enabling goals (see below) in particular the investment commitments made by public and private actors for maintaining, upgrading or expanding infrastructure, but also the establishment of adequate guidelines and regulations for infrastructure operation and development.

\subsubsection{Target Area B3: Energy Efficiency}

All global assessments demonstrate that efficiency improvements in resource use will be "the name of the game" in the coming decades, across sectors such as transport, buildings, appliances, industrial 
processes or agriculture. Current trends regarding efficiency go in different directions, but overall, there is great potential across sectors and an increasing political interest internationally. Ongoing and planned policy frameworks would support the implementation of an efficiency target. On the supply side, there is a rapidly rising share of more efficient power generation technologies. On the user side, the electrification of transport, industrial processes and transport systems offers potentials for major efficiency improvements. Although efficiency measures are usually "low hanging fruit" as highly profitable investments, and not a controversial agenda, they have proven difficult to implement in many places, due to institutional, political, market, or knowledge gaps and barriers [36].

Global energy intensity has fallen significantly in the last three decades, at a rate of $1.2 \%$ per year. SE4All calls for a doubling of this rate, producing a $40 \%$ reduction by 2030 . While a doubling of the rate is ambitious, sector estimates for buildings, appliances, industrial processes, and transport suggest that it is achievable [34]. Building on existing frameworks, goals can be set around overall energy use and energy used per value added in different sectors, but also related to physical units, e.g., per square meter in buildings and per vehicle $\mathrm{km}$ (see also [60]). Electrification of industrial processes and transport is an important aspect of efficiency improvements overall. This suggests that setting goals for electricity to grow slightly can create important returns in emissions savings in these sectors.

For efficiency targets, it is useful to separate what can be achieved when new buildings, plants and processes are being built and what can be done in retrofitting mode. SE4All suggests a doubling of the global rate of efficiency improvement to 2030. This corresponds relatively well with the SEI global scenario [36] and Netherlands Environmental Assessment Agency's (PBL) "Challenge" pathways [35] which require an energy intensity reduction overall (as energy use per unit of economic output) by around $2.5 \%$ per year. However, specific efficiency targets need to be tailored to specific industry branches and the national context, taking into account both technical and economic feasibility.

\subsection{Global Public Goods}

The third tier concerns functions in the global society that display public good characteristics such as the stability and functioning of markets, security, and climate change. Target areas in this tier would normally be established at the global or international level, but with differentiated national commitments to contribute to them. In contrast to the first and second tier target areas, these global targets are not likely to change over time.

\subsubsection{Target Area C1: Greenhouse Gas Emissions}

Countries worldwide agreed on limiting global average temperature increase to maximum $2{ }^{\circ} \mathrm{C}$ above pre-industrial levels $[61,62]$. It is estimated that this requires cuts in greenhouse gas (GHG) emissions of $35-55 \%$ by 2050 compared to 1990 emissions levels [63]. Recent analysis has shown that achieving simultaneously the SE4ALL objectives would be consistent with such a global climate target, provided that they are implemented globally [51]. Furthermore, they should be complemented by other GHG mitigation measures, including halting deforestation and limiting non- $\mathrm{CO}_{2}$ emissions from agriculture. The pathways aiming at the $2{ }^{\circ} \mathrm{C}$ target as presented in Figure 3 conclude that around $40 \%$ of cumulative emission reductions towards 2050 should come from non- $\mathrm{CO}_{2}$ and non-energy sources, including deforestation and agriculture and reductions need to continue long after 2030. 
However, the major (and increasing) share of GHG emissions emanate from energy production and use. Within the energy sector, transport accounts for $23 \%$ of energy-related $\mathrm{CO}_{2}$ emissions, buildings $10 \%$, power sector $40 \%$, and industry around $20 \%$ each with specific difficulties and opportunities with respect to GHG abatement (see also goal area B1).

SDG targets could be set with respect to long-term global GHG emissions and levels differentiated for countries, as well as specific sectoral targets, bearing in mind the most cost effective low-emissions development strategies. Of particular importance is the opportunity to develop for low-income countries-even when this means increasing national GHG emissions. It should be stressed that providing universal access to modern energy services does not necessarily conflict with mitigating climate change, as potential increasing GHG emissions from fossil-fuel use are to a large degree compensated by reduced deforestation and black carbon emissions, although comparisons are difficult since time horizons differ $[35,40,41]$. Coordination with a future global climate agreement regarding target setting and monitoring is essential. Indeed, all reporting and measurements could be carried out within the UN framework convention.

\subsubsection{Target Area C2: Energy Security}

Energy security, sometimes framed as the uninterrupted provisioning of energy, is a high priority in all societies. The lack of energy security is today often considered a national or regional political concern. However, while energy security is partly an outcome of the national or regional management of the physical resource base and energy infrastructure (handled in the second tier in our framework), it is to a significant degree a function of international cooperation in the global political and market systems, such as the establishment of international rules for supply infrastructures and for market transactions. So while countries can do things to enhance their energy security nationally, and energy as a commodity is not a public good, the overall energy security context (within which the national strategy will always be framed) displays distinct global public good characteristics that can only be enhanced through cooperation and collective action at the international level $[64,65]$.

Current trends in global energy reserves have been largely positive from a security perspective. For example, in recent years, new extraction techniques for both gas (e.g., shale) and oil (e.g., deep sea) have expanded the availability of these fossil energy types and diversified supplies. However, energy security is also about managing the technical and political issues that may prevent countries from accessing energy. Dimensions of energy security, such as availability, accessibility and affordability [66], are closely linked and all tie into the functioning of the global energy market. For instance, with the development of international energy markets, supply shortages and dependencies manifest in prices, making the issue of functioning markets also integral to energy security [67]. Compromised accessibility due to "above-ground" problems has contributed to high and volatile prices on oil in recent years. Due to these interlinkages, SDG targets for energy security can be set on a variety of parameters, such as diversity of energy sources, diversity of suppliers and supply routes, both at national and international levels, diversification of energy sources, but also, for individual countries, factors such as the import mix, and for outcome indicators such as market volatility. 
Figure 4. SDG framework for energy: eight target areas in three tiers.

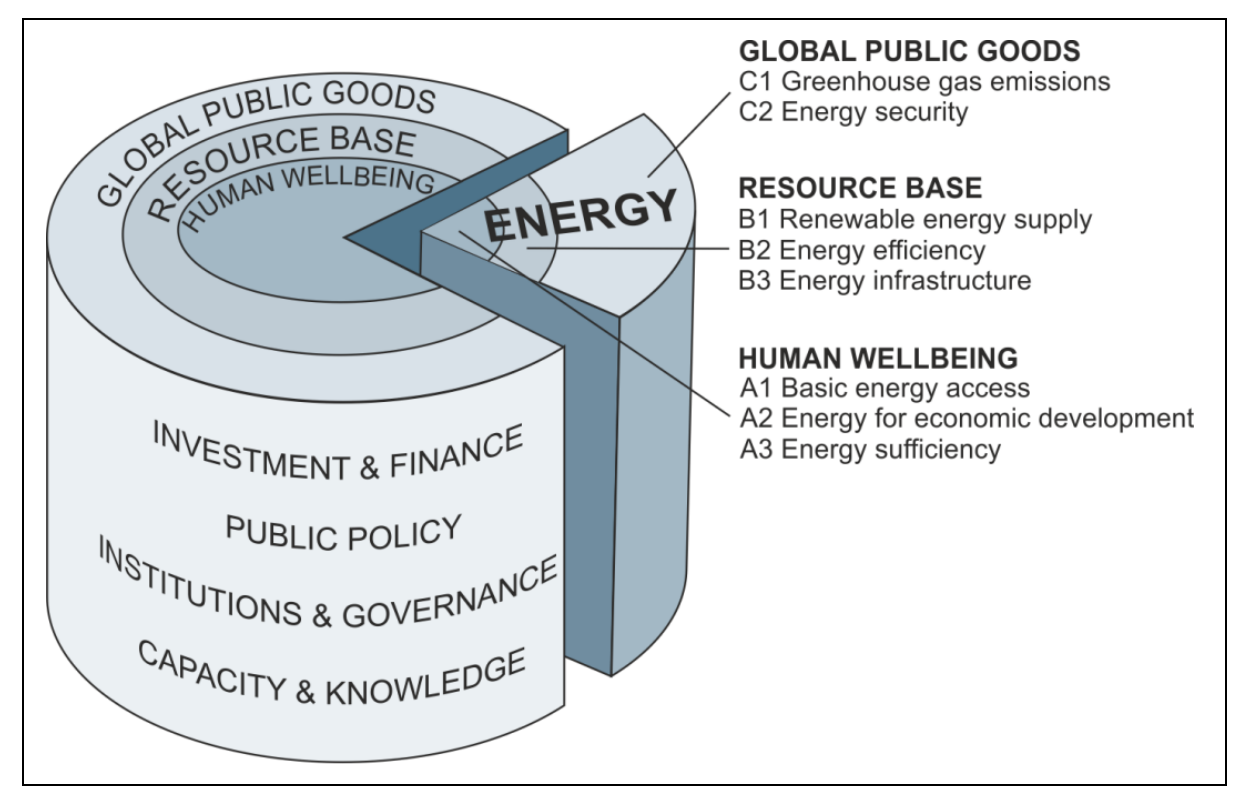

The eight target areas thus cover the SE4All agenda (energy for basic access and for development, renewables and efficiency) but also aspects that are key in a more universally relevant agenda (sufficiency and infrastructure development) as well as global public goods (energy security, climate) that need to be managed. In comparison, the High-level Panel suggestion for their goal "Secure Sustainable Energy" simply took the SE4All agenda and added an item about removing fossil fuel subsidies [5].

\section{Enabling Goals: Four Layers of Interventions to Get Us There}

Adding to the ultimate goals and target areas within them, enabling goals in four "layers" can be formulated. These layers address the systemic and structural barriers to development that can be addressed through, in particular, public intervention (and for which governments can to some degree be held accountable). The layers are universally relevant (for all countries and for all SDGs), and can be formulated at global, national and subnational scales. Below we introduce briefly what these four layers of enabling goals could entail for the energy sector, and how they relate to the ultimate goals. Examples are given but are only illustrative. It is conceivable, but potentially too ambitious in practice, to elaborate a more comprehensive matrix with enabling targets in each layer for each of the ultimate target areas.

\subsection{Capacity \& Knowledge}

A number of capacities are crucial in order to develop and adopt successful energy strategies. Efforts need to be made for an overall strengthening of human and institutional capacities and sharing of knowledge. This includes capacity building efforts at national levels but also international science and technology collaborations and technology transfer facilities.

Goals for capacity and knowledge will be predominantly of qualitative nature but could be established for building or improving on existing national institutions to manage and process market 
data (for target area C2), resource mapping (for B1), energy modeling and planning (across goals), training programs of policy makers and engineers, how to improve procedures for contracting and procurement, and technical assistance facilities. Finally, appropriate policy assessment frameworks need to be established to develop the knowledge base that will enable mitigation of environmental and social risks associated with energy development options.

\subsection{Institutions \& Governance}

The establishment of stable and strong institutional arrangements and rule frameworks form the foundation of social coordination between different actors. Governance for "bottom-up" societal processes is an essential part of the energy transformation. Such arrangements enable and ensure that policies and investments are directed, implemented and monitored in appropriate ways, in transparent and accountable systems, engaging with relevant stakeholders.

Goals for governance and institutions will be predominantly of a qualitative nature. They could include time tables for the establishment of better and updated energy planning systems, licensing/permit granting procedures and monitoring frameworks that take into account the environmental and social impacts of for instance renewable energy expansion and infrastructure (for B1 and B2), transparency and stakeholder engagement rules in energy planning (for B1 and B3) and accountability mechanisms for delivery of energy access (for A1).

A key institutional aspect is the functioning of energy markets. This is a long-standing political priority in its own right in many parts of the world. Markets are sometimes national (e.g., natural gas in the US) but to an increasing degree international and even global (for some segments such as oil or solar PV panels). Energy markets is still an enabling goal, as it is a means to an end of tackling a whole range of energy and climate challenges and efficient use of limited resources. Functioning energy markets would mobilize resources for investments in the sector needed to attain the other goals, including energy security, basic energy access, and renewable supply [68].

\subsection{Public Policy}

Promotion of national and international policies including standard setting, economic instruments, R\&D support, labels, and other measures, is required to regulate and incentivize actors. Of particular importance are policy interventions that can help overcome barriers to the deployment of sustainable energy services and technologies and drive innovations forward in socio-technical systems.

Public policy goals can be quantitative in terms of specific levels of carbon taxation (for C1) , efficiency standards (for B3), environmental standards, costs of subsidies or other support measures offered for basic energy access (for A1) or renewable energy (for B1) or investment support for infrastructure (for B2 or A1) but will sometimes be of more qualitative nature, with clear time tables for implementation, such as the establishment of a national industrial energy efficiency program (for B3), removal plans for fossil fuel subsidies [69] (for C1 and B3) or an information campaign for energy savings (for A3) by a certain target year). 


\subsection{Investment \& Finance}

The energy challenge calls for increasing energy-related investment-e.g., in access to services, technologies and infrastructures. Enabling mechanisms include loan guarantees, risk insurances, climate finance, and credit schemes.

How to finance the investment can also be framed as goals taking into account equal and fair burden sharing between countries, e.g., goals for higher-income countries in terms of providing international (donor) financing for projects through some global mechanism. Goals need to reflect capacities of different actors to mobilize resources-be it private sector, the multilateral institutions (such as GEF or the green fund) or the national governments. It is clear that the financing needs exceed the capacity of many developing countries. International finance from developed countries will be needed, and is consistent with principles of equity, effectiveness, and international commitments as reaffirmed in the 2012 UN Conference on Sustainable Development.

In contrast to the three other enabling goals, the investment and finance category lends itself naturally to quantitative goals based on global modeling and estimates of "what it takes". According to the International Energy Agency (IEA), investment needs for modern energy access (for A1) equal ca. 50 billion per year up to 2030. Investment needs for energy infrastructure (for B2) more generally are much higher, and has been estimated at \$270 trillion (2010-2050). Global investment in renewable energy is now routinely published with both country and asset class disaggregation [70]. Enhancing energy security (C3) is dependent on investments in back up power and transmission network capacity. Meeting IEA's low-carbon scenario $(\mathrm{C} 1)$ requires an additional \$36 trillion. Implementing it would require a five to ten fold increase in annual investment compared to today [71]. However, these investments are usually profitable: the additional $\$ 36$ trillion would be offset by $\$ 100$ trillion in savings from reduced use of fossil fuel. There will also be many opportunities for leapfrogging, synergies in pursuing several goals at ones in investment strategies [33], and avoiding high-carbon infrastructure lock-in.

\section{Examining SDG Coherence through Pathways Assessment}

The SDG agenda will necessarily combine a diverse range of areas that may be in conflict with each other. Only within the energy goal, target areas such as basic access, energy for economic development, sustainable resource use, efficiency, infrastructure, climate protection, air pollution control, and energy security must be pursued in parallel. Can these targets be pursued without trade-offs between them? In addition, there will be potentially 6-12 additional SDGs (health, education, food security, etc.). Can all these goals be implemented through strategies that create more synergy than conflict with other SDGs? Analyzing such coherence of policies is in itself a cumbersome undertaking requiring detailed analysis not only of policy goals, but also of instruments and implementation practices [72]. For each jurisdiction that establishes goals, an integrated view is needed on how goals, targets and instruments interact in the implementation of the strategies and policies.

How can this view be developed? A pathways assessment is a policy-analytical approach to establish an integrated perspective over time across goals as implementation proceeds, while at the same time describing what alternative policy strategies and choices can be pursued. The formulation 
and assessment of pathways will help identify trade-offs and synergies that are likely to emerge as policies and technologies are deployed towards achieving the SDGs. This will give policy makers information to proactively take measures and actions to mitigate trade-offs and enhance potential synergies.

Pathways assessments can and should be carried out at both national and global scales. While much of the methods and analytics will be implemented by research institutes, national governments are the natural focal points and users of the assessment. At the global level, the newly installed High Level Political Forum could supervise and coordinate methods, assumptions, and joint data sets. A global example of a pathways assessment is PBL's "Challenge" pathways, which are all designed to achieve a set of ambitious sustainable development objectives [35]. The pathways integrate long-term climate stabilization, air pollution control, and universal energy access, halting biodiversity loss and providing sufficient food for all people. They combine different combinations of technological measures and consumption changes. All pathways require a significant increase in agricultural yields and decarbonization rates. Figure 5 shows the global cumulative emission reductions for the three pathways. A focus on large scale global technologies reduce deforestation emissions through increasing agricultural yields (also important for halting biodiversity loss), carbon-capture and storage, and nuclear energy, while more localized food and energy production favor renewables and efficiency improvements. Finally, a focus on consumption, including reduced meat consumption and a significant increase in public transport, decreases emissions from deforestation and increases energy efficiency in the transport sector, thereby lowering the reduction requirement through large scale global or more localized technologies.

Figure 5. Alternative trajectories of global greenhouse gas emission reductions, while aiming for a broad range of long-term sustainability targets [49].
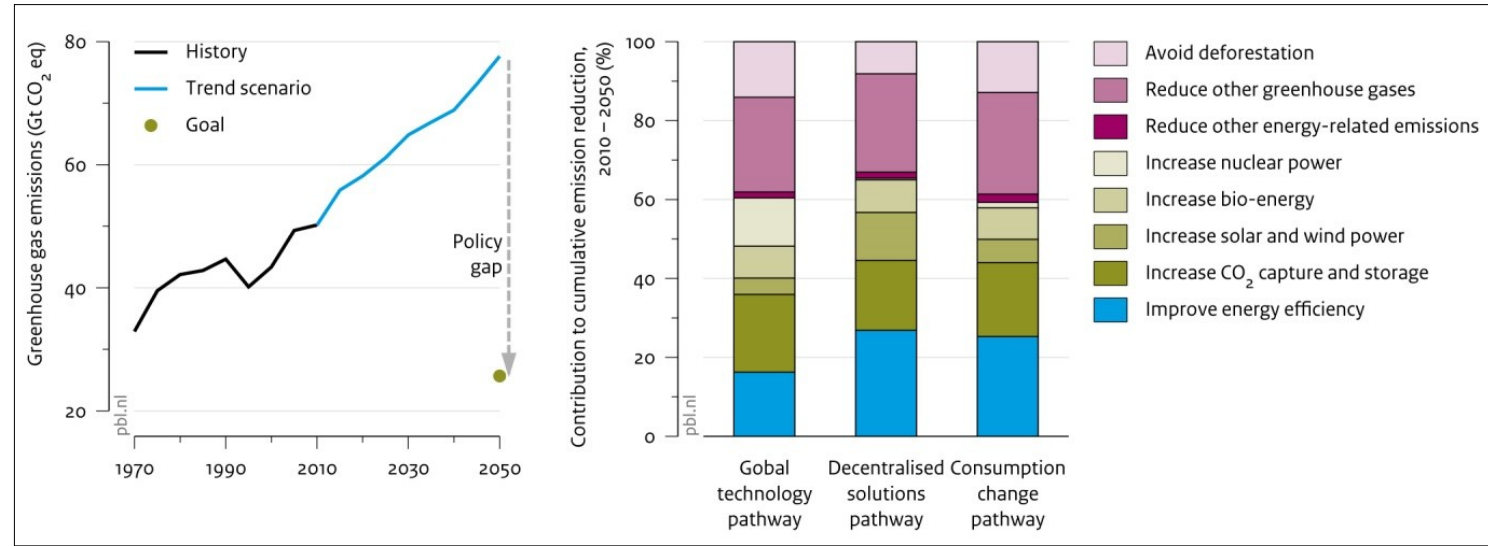

As mentioned, although Figure 5 only presents greenhouse gas emissions trajectories, the illustrative pathways cover energy, food and biodiversity using an integrated assessment methodology. This offers one approach for how countries could visualize their development trajectory based on the pursuit of SDGs. Once a broader range of SDGs has been proposed for a country, specific pathways could be elaborated to examine how different countries are doing across the multiple target areas included in the proposed SDGs.

With multiple goals, each pathway will face specific trade-offs. Combining elements of the pathways could make the response strategy more robust in terms of implementation, taking into 
account that different elements appeal to different actors. Thus, the pathways can be unpacked to different contexts and capacities. Where countries find themselves at different starting points, pathways can be examined that in the long term converge in economic development, human wellbeing and observing sustainability considerations. Figure 6 illustrates this by describing potential trajectories of energy demand taking into account equity considerations between countries. In this normative scenario developed by SEI, low-income societies (such as India) will continue to grow their energy use up to 2050, emerging economies continue to increase their energy use until 2025 but then start coming down, and high-income regions begin decreasing their energy use already around 2015 [36].

Figure 6. Evolution of energy demand by sector in three regions according to a normative scenario of development for all within a two degree warming constraint [36].

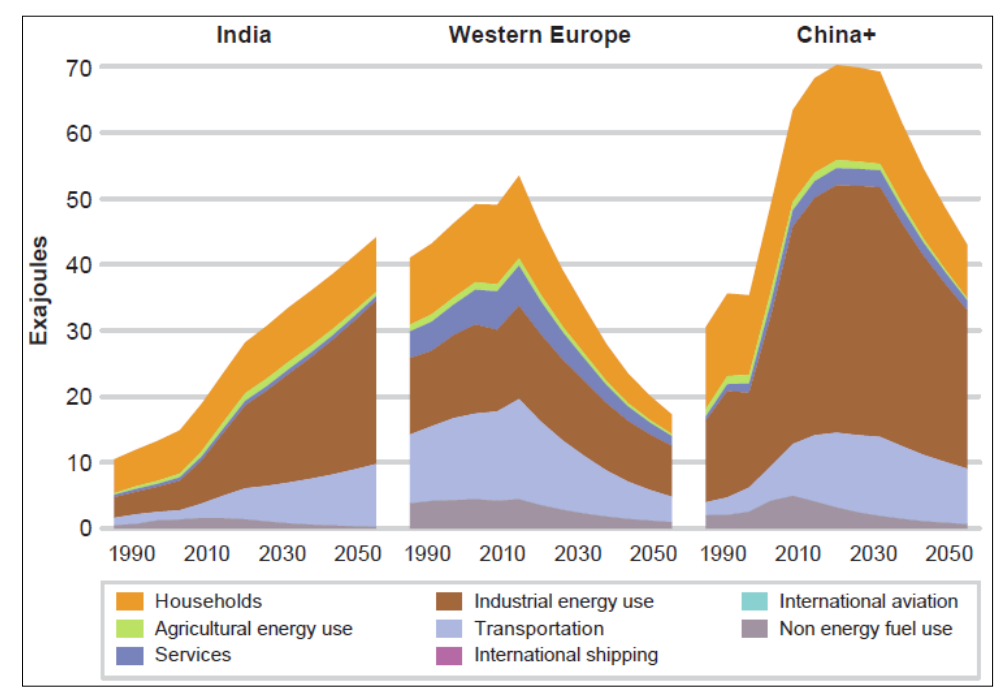

Figure 6 shows that the SDG energy agenda, and associated pathways, will be different for different types of countries. The development priority for many low-income countries is to ensure universal access to energy services and secure a potential for economic growth, whereas middle-income and emerging economies, where growth is already occurring fast, need to develop their energy systems in ways that decouple growth from energy consumption and greenhouse gas emissions. Finally, high-income countries need to decarbonize their energy sectors and reach new levels of efficiency performance. For advanced societies, with relatively clean energy systems, both efficiency and reduced levels of energy consumption are required (see Figure 7).

Figure 7. Illustration of national focus areas for energy depending on level of development.

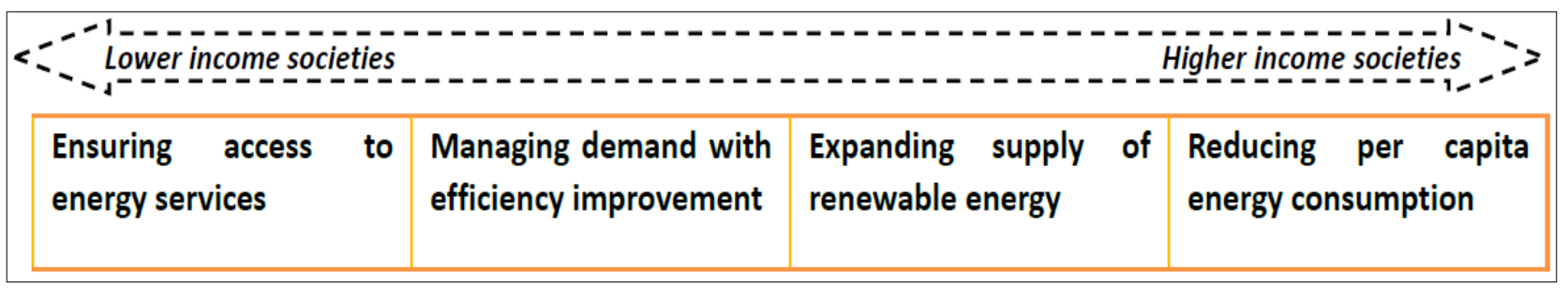

How does this differentiation play out in practice? The World Bank recently identified 20 "high impact" countries, which have a particularly large weight in terms of electricity access deficit, 
non-solid access deficit, and primary energy demand (see Figure 8). The first group accounts for about two-thirds of the global electrification deficit, the second accounts for about four-fifths of the global deficit in access to non-solid fuel, and the third accounts for about four-fifths of global energy consumption. [71] While the group of 20 countries for electricity access deficit and non-solid fuel access deficit overlap with the exception of China, the group is fairly different for energy demand, which are mainly advanced industrial countries plus a few populous developing countries.

Figure 8. Overview of high impact countries, 2010 [73].

\begin{tabular}{|c|c|c|c|c|c|c|}
\hline & $\begin{array}{l}\text { ELECTRICITY ACCESS DEFICIT } \\
\text { (MILLIONS OF PEOPLE) }\end{array}$ & NON & $\begin{array}{l}\text {-SOLID FUEL ACCESS DEFICIT } \\
\text { (MILLIONS OF PEOPLE) }\end{array}$ & & $\begin{array}{l}\text { RIMARY ENERGY DEMAND } \\
\text { (EXAJOULES) }\end{array}$ & \\
\hline INDIA] & & INDIA] & & CHINA] & & 107.4 \\
\hline NIGERIA- & 82.4 & CHINA & 612.8 & USA- & 92.8 & \\
\hline BANGLADESH & 66.6 & BANGLADESH & \begin{tabular}{l|l}
134.9
\end{tabular} & RUSSIA & 29.4 & \\
\hline ETHIOPIA & 63.9 & INDONESIA $^{-1}$ & 131.2 & INDIA & 29 & \\
\hline CONGO, DR & 55.9 & NIGERIA & 117.8 & JAPAN & 20.8 & \\
\hline TANZANIA & 38.2 & PAKISTAN & \begin{tabular}{|l|l|} 
& 110.8
\end{tabular} & GERMANY & 13.7 & \\
\hline KENYA & 31.2 & ETHIOPIA & 81.1 & BRAZIL & 11.1 & \\
\hline SUDAN & 30.9 & CONGO, DR & 61.3 & FRANCE- & 11 & \\
\hline UGANDA & 28.5 & VIETNAM & 49.4 & CANADA & 10.5 & \\
\hline MYANMAR & 24.6 & PHILIPPINES & 46.2 & S. KOREA- & 10.5 & \\
\hline MOZAMBIQUE & 19.9 & MYANMAR & 44 & IRAN & 8.7 & \\
\hline AFGHANISTAN & 18.5 & TANZANIA & 42.3 & INDONESIA & 8.7 & \\
\hline KOREA, DR & 18 & SUDAN & 34.6 & UK & 8.5 & \\
\hline MADAGASCAR & 17.8 & KENYA ${ }^{-1}$ & 32.6 & MEXICO- & 7.5 & \\
\hline PHILIPPINES & 15.6 & UGANDA & 32.2 & ITALY & 7.1 & \\
\hline PAKISTAN & 15 & AFGHANISTAN & 26.7 & S. ARABIA & 7.1 & \\
\hline BURKINA FASO & 14.3 & NEPAL & 24.6 & S. AFRICA & 5.7 & \\
\hline NIGER & 14.1 & MOZAMBIOUE & 22.2 & UKRAINE & 5.5 & \\
\hline INDONESIA & 14 & KOREA, DR & 22.2 & SPAIN & 5.3 & \\
\hline MALAWI] & 13.6 & GHANA & 20.4 & AUSTRALIA & 5.2 & \\
\hline
\end{tabular}

Differentiation of targets does not mean that lower-income countries should not invest effort in energy efficiency or renewable energy, but possible trade offs in meeting different goals need to be considered and the prioritizations need to be made. Each case needs to be carefully examined in terms of costs and benefits for the environment and people before it is approved and for this, carefully designed national and local policy, as well as targets and indicators are critical. All countries need to be mindful of the risks and costs associated with technology lock-in, a particularly persistent problem in the energy sector due to the longevity of the infrastructure. In fact, leapfrogging directly into renewables may be a very attractive economic development strategy for countries with renewable resource endowments (such as bioenergy, wind, geothermal, or solar).

Using a pathways approach, the most beneficial strategy overall can be identified bearing in mind the combination of costs, benefits and risks on the combination of development goals within the energy sector (e.g., supply cost, resilience to disruptions, long term import-dependency, and GHG mitigation) as well as against other development goals (health, food, etc.).

\section{Conclusions and Implications}

This paper has presented a three-tiered framework for the formulation of SDGs and has provided the basic building blocks for the development of target areas in the case of energy. The pursuit of human wellbeing is at the core of this framework, conditioned and constrained by scarce resources and by the rights of other people to pursue their wellbeing. The resource base for development, the second tier, is constituted by interacting (and evolving) social, environmental, and economic capital bases at 
different scales-from local to global. These are in turn dependent on the provisioning of global public goods forming the third tier.

The framework thus advocates an integrated approach. Rather than presenting environmental, social and economic pillars as goal areas, these would be the constitutive dimensions of each of the SDGs across the tiers. Applying this to the energy issue, social and economic dimensions of development are at the core tier, through the delivery of modern energy services for human wellbeing. Although energy was not considered as an MDG in of itself, lack of basic access to modern energy contributes to poverty and hinders the achievement of several of the MDGs, and negatively affects women and children. Beyond basic energy access, the human wellbeing tier includes targets on energy for economic development and energy sufficiency. Over time, in order to enable durable poverty alleviation, the initially modest aspirations when it comes to energy access must be adapted to much higher levels of energy service demand beyond household energy use into growth of public services, industry and businesses $[73,74]$. In the two outer tiers, economic and environmental dimensions are nested that set the long-term sustainability of the sector. The second tier includes targets on renewable energy supply, energy efficiency, and infrastructure, and the third tier includes targets on energy security and on greenhouse gas emissions.

The development of this framework has pointed towards a number of key principles for SDGs:

- A shared and universal development agenda based on human wellbeing. SDGs must be crafted in a way that is politically acceptable in the multilateral political system, where currently trust between nations has been eroded. This requires that they are rooted in common concerns and priorities. A tractable foundation, and strongly institutionalized norm, is the pursuit of human wellbeing and opportunity to prosper for all societies. An important premise for this is equality: increasing income equality over time delivers benefits directly in terms of wellbeing but is also important for economic development.

- Linking human wellbeing to the resource base and global public goods. For human wellbeing to be achievable for all and over the long term, targets must address the development of the supporting resource base. Human wellbeing and sustainability are thus tightly linked and must be integrated as development goals. This requirement is anchored in the fundamental premise that resources are scarce and the development of one actor must be pursued respecting the right of the other to access resources to develop.

- Enabling goals to complement ultimate goals should be established. We propose four key categories: capacity \& knowledge development, governance \& institutions, public policy, and investment \& finance. These may be treated in the UN system and the broader international cooperation framework as "means of implementation".

- Differentiation in time and space. The development challenge looks different in different countries. Priorities should be tailored from country to country, depending on resources, capacities and the level of development. Universal goals at the global level thus need to disaggregate into differential sets of specific targets for different countries. Second, targets need to be dynamic in taking into account changes and development patterns over time. For instance, when South Asia and Sub-Saharan Africa gain universal energy access, by 2030 if we meet our current goals, then they will have to move up the "energy ladder". In the long term, 
strong economic development in lower-income economies will lead to both greater income equality both between and within countries and an alignment of national development agendas.

- Pathways to ensure integration and coherence: An SDG framework must be coherent so that different target areas do not counteract one another-both within a goal and between goals. This requires integration so that environment, social and economic aspects come together in each development sector rather than being treated as separate pillars. The coherence of the agenda can be tested through assessments of aggregate development pathways that articulate the technologies, practices and governance systems and enable us to trace and understand changes over time and their interactions. For example, universal basic access has already been demonstrated to be coherent with climate change mitigation, having a very marginal net effect on global greenhouse gas emissions.

The presented framework and resulting development agenda is universally relevant, but depending on national circumstances, the national emphasis on different aspects should be differentiated. Achieving universal relevance has implied a certain complexity, which in itself is a limitation from a political perspective. The complexity will make the framework less communicable. It will not be possible to trace or communicate progress on "Secure Sustainable Energy" through one single headline indicator. At the same time, the presented architecture is not comprehensive either. Many sustainable development concerns connected to energy systems have not been included, such as the water-energy-food nexus, risks of accidents or pollution generated by thermal combustion systems. Ultimately, the framework can therefore be criticized for being too complex as well as too simplistic. Still, as the agenda has moved from MDGs to SDGs, the added complexity of the challenge does imply a higher degree of conceptual richness than in the MDG system.

\section{Acknowledgments}

This paper has benefited from conversations and framing discussions in the Independent Research Forum (IRF2015), a collaboration of 12 sustainable development research institutes and think tanks from across the globe that supports and informs the intergovernmental process on SDG. We thank Emma Wilson and Ben Garside (IIED), Simon Holberg (IGES) and Peter Hazlewood (WRI) for comments on an earlier draft, and Detlef van Vuuren (PBL), Marcel Kok (PBL), Eric Zusman (IGES) and Ikuho Miyazawa (IGES) for valuable input and comments on this paper. We also would like to thank the three anonymous referees and the guest editors of this special issue for valuable comments.

\section{Conflicts of Interest}

The authors declare no conflict of interest.

\section{References}

1. UN. The Future We Want. In Proceedings of the Rio+20 United Nations Conference on Sustainable Development, Rio de Janeiro, Brazil, 20-22 June 2012.

2. Evans, A. Climate, Scarcity and Sustainability in the Post-2015 Development Agenda; New York University, Center on International Cooperation: New York, NY, USA, 2012. 
3. Melamed, C.; Scott, A.; Mitchel, T. Separated at Birth, Reunited in Rio? A Roadmap to Bring Environment and Development Back Together; Overseas Development Institute (ODI): London, UK, 2012.

4. UNSDSN. An Action Agenda for Sustainable Development; Sustainable Development Solutions Network: New York, NY, USA, 2013.

5. High-level Panel. A New Global Partnership: Eradicate Poverty and Transform Economies through Sustainable Development; United Nations: New York, NY, USA, 2013.

6. High-level Panel Secretariat. People first-a Post 2015 Development Agenda. Working paper for the second HLP meeting in London. Unpublished work, 2012.

7. Sachs, J.D. From millennium development goals to sustainable development goals. Lancet 2012, 379, 2206-2211.

8. Griggs, D.; Stafford-Smith, M.; Gaffney, O.; Rockström, J.; Öhman, M.; Shyamsundar, P.; Steffen, W.; Glaser, G.; Kanie, N.; Noble, I. Policy: Sustainable development goals for people and planet. Nature 2013, 495, 305-307.

9. United Nations Environment Programme (UNEP). Embedding the Environment in Sustainable Development Goals. UNEP Post-2015 Discussion Paper 1; UNEP: Nairobi, Kenya, 2013.

10. Evans, A.; Steven, D. Sustainable Development Goals-a Useful Outcome from Rio+20?; New York University: New York, NY, USA, 2012.

11. Raworth, K. A Safe and just Space for Humanity: Can We Live inside the Doughnut? Oxfam International: London, UK, 2012.

12. United Nations Global Compact (UNGC). Corporate Sustainability and the United Nations Post2015 Development Agenda: Perspectives from UN Global Compact Participants on Global Priorities and How to Engage Business Towards Sustainable Development Goals; UNGC: New York, NY, USA, 2012.

13. Bernstein, S. The Compromise of Liberal Environmentalism; Columbia University Press: New York, NY, USA, 2001.

14. Kharas, H. The Emerging Middle Class in Developing Countries; OECD: Paris, France, 2010.

15. Chen, S.; Ravallion, M. More Relatively-Poor People in a Less Absolutely-Poor World; Policy Research Working Paper Series 6114; The World Bank: Washington, DC, USA, 2012.

16. Gewirth, A. Reason and Morality; University of Chicago Press: Chicago, IL, USA, 1978.

17. Arrow, K. Social Choice and Individual Values; Wiley: New York, NY, USA, 1963.

18. Dasgupta, P. Human Wellbeing and the Natural Environment; Oxford University Press: Oxford, UK, 2001.

19. Sen, A. Capability and Well-Being. In The Quality of Life; Sen, A., Nussbaum, M.C., Eds.; Oxford University Press: Oxford, UK, 1993.

20. Sen, A. Development as Freedom; Oxford University Press: Oxford, UK, 1999; p. 366.

21. Jackson, T. Prosperity without Growth; Earthscan: London, UK, 2009.

22. Martínez, D.M.; Ebenhack, B.W. Understanding the role of energy consumption in human development through the use of saturation phenomena. Energy Policy 2008, 36, 1430-1435.

23. Arrow, K.; Dasgupta, P.; Goulder, L.; Daily, G.; Ehrlich, P.; Heal, G.; Levin, S.; Mäler, K.G.; Schneider, S.; Starrett D.; Walker, B. Are we consuming too much? J. Econ. Perspect. 2004, 18, $147-172$. 
24. Hamilton, C.; Denniss, R. Affluenza when too much is never Enough; Allen \& Unwin: Sydney, Australia, 2005.

25. Robbins, L. An Essay on the Nature and Significance of Economic Science; MacMillan and Co.: London, UK, 1935.

26. Department for International Development (DFID). Sustainable Livelihoods Guidance Sheets; DFID: London, UK, 2000.

27. Hamilton, K. Genuine Saving as a Sustainability Indicator; The World Bank: Washington, DC, USA, 2000; p. 15.

28. Olsen, M. The Logic of Collective Action: Public Goods and the Theory of Groups; Harvard University Press: Cambridge, MA, USA, 1965.

29. Crutzen, P.J.; Stoermer, E.F. The 'anthropocene'. Glob. Change Newsl. 2000, 41, 17-18.

30. Pierre, J.; Peters, G. Governing Complex Societies; Palgrave Macmillan: Basingstoke, UK, 2006.

31. Van Vuuren, D.; Nakicenovic, N.; Riahi, K.; Brew-Hammond, A.; Kammen, D.; Modi, V.; Nilsson, M.; Smith, K.R. An energy vision: Transformation toward sustainability-interconnected challenges and solutions. Curr. Opin. Environ. Sustain. 2012, 4, 18-34.

32. The Secretary-General's High-level Group on Sustainable Energy for All. Sustainable Energy for All: A Global Action Agenda; United Nations: New York, NY, USA, 2012.

33. Global Energy Assessment (GEA). Global Energy Assessment: Towards a Sustainable Future; Cambridge University Press: Cambridge, UK, 2012.

34. International Energy Agency (IEA). World Energy Outlook 2012; IEA: Paris, France, 2012.

35. PBL. Roads from Rio+20: Pathways to Achieve Global Sustainability Goals by 2050; Van Vuuren, D.P., Kok, M.T.J., Eds.; PBL Netherlands Environmental Assessment Agency: Den Haag/Bilthoven, The Netherlands, 2012.

36. Nilsson, M.; Heaps, C.; Persson, Å.; Carson, M.; Pachauri, S.; Kok, M.; Olsson, M.; Rehman, I.; Schaeffer, R.; Wood, D.; et al. Energy for a Shared Development Agenda: Global Scenarios and Governance Implications; Stockholm Environment Institute: Stockholm, Sweden, 2012.

37. UN Energy. The Energy Challenge for Achieving the Millenium Development Goals; United Nations: New York, NY, USA, 2005.

38. Pachauri, S.; van Ruijven, B.; Nagai, Y.; Riahi, K.; van Vuuren, D. Pathways to achieve universal household access to modern energy by 2030. Environ. Res. Lett. 2013, 8, 024015.

39. Lim, S.; Vos, T.; Flaxman, A.; Danaei, G.; Shibuya, K.; Adair-Rohani, H.; Amann, M.; Anderson, R.; Andrews, K:; Aryee, M.; et al. A comparative risk assessment of burden of disease and injury attributable to 67 risk factors and risk factor clusters in 21 regions, 1990-2010: A systematic analysis for the Global Burden of Disease Study 2010. Lancet 2013, 380, 2224-2260.

40. International Energy Agency (IEA). Energy Poverty: How to Make Modern Energy Access Universal? Special Early Excerpt of the World Energy Outlook 2010 for the UN General Assembly on the Millennium Development Goals; IEA: Paris, France, 2010.

41. Fatmi, Z.; Rahman, A.; Kazi, A.; Kadir, M.; Sathiakumar, N. Situational Analysis of Household Energy and Biomass Use and Associated Health Burden of Indoor Air Pollution and Mitigation Efforts in Pakistan. Int. J. Environ. Res. Public Health 2010, 7, 2940-2952.

42. Pachauri, S. Reaching an international consensus on defining modern energy access. Curr. Opin. Environ. Sustain. 2011, 3, 235-240. 
43. AGECC. Energy for a Sustainable Future: Secretary-General's Advisory Group on Energy and Climate Change; United Nations: New York, NY, USA, 2010.

44. Goldemberg, J.; Johansson, T.B.; Reddy, A.K.N.; Williams, R.H. Basic needs and much more with one kilowatt per capita. Ambio 1985, 14, 190-200.

45. Smil, V. Energy at the Crossroads. Global Perspectives and Uncertainties; MIT Press: Cambridge, MA, USA, 2003.

46. Cabraal, A.; Barnes, D.F.; Agarwal, S.G. Productive uses of energy for rural development. Annu. Rev. Environ. Resour. 2005, 30, 117-144.

47. Martinez, D.M.; Ebenhack, B.W. Understanding the role of energy consumption in human development through the use of saturation phenomena. Energy Policy 2008, 36, 1430-1435.

48. WWF and Ecofys. The Energy Report-100\% Renewables by 2050. WWF: Gland, Swizerland, 2011.

49. Girod, B.; van Vuuren, D.P.; de Vries, B. Influence of Travel Behavior on Global $\mathrm{CO}_{2}$ Emissions. Transport. Res. A-Pol. 2013, 50, 183-197.

50. Steinberger, J.K.; Roberts, J.T. From constraint to sufficiency. The decoupling of energy and carbon from human needs, 1975-2005. Ecol. Econ. 2010, 70, 425-433.

51. REN21. Global Status Report for 2012; REN21 Secretariat: Paris, France, 2012.

52. Riahi, K.; Dentener, F.; Gielen, D.; Grubler, A.; Jewell, J.; Klimont, Z.; Krey, V.; McCollum, D.L.; Pachauri, S.; Rao, S.; et al. Energy Pathways for Sustainable Development. In The Global Energy Assessment: Toward a More Sustainable Future; Cambridge University Press: Cambridge, UK, 2012.

53. Rogelj, J.; McCollum, D.L.; Riahi, K. The UN's 'Sustainable Energy for All' initiative is compatible with a warming limit of $2^{\circ} \mathrm{C}$. Nat. Clim. Change 2013, 3, 545-551.

54. Luderer, G.; Krey, V.; Calvin, K.; Merrick, J.; Mima, S.; Pietzcker, R.C.; van Vliet, J.; Wada, K.; The role of renewable energy in climate stabilization: results from the EMF27 scenarios. Clim. Change 2013, in press.

55. Van Vuuren, D.P.; Riahi, K. The relationship between short-term emissions and long-term concentration targets-A letter. Clim. Change 2011, 104, 793-801.

56. Intergovernmental Panel on Climate Change (IPCC). Special Report on Renewable Energy Sources and Climate Change Mitigation; IPCC: Bonn, Germany 2011.

57. Bringezu, S.; Schutz, H.; O’Brien, M.; Kauppi, L.; Howarth. R.; McNeely, J. Assessing Biofuels; UNEP-International Panel for Sustainable Resource Management: Paris, France, 2009.

58. Van Vuuren, D.P.; van Vliet, J.; Stehfest, E. Future bio-energy potential under various natural constraints. Energy Policy 2009, 37, 4220-4230.

59. Van Vuuren, D.P.; Bellevrat, E.; Kitous, A.; Isaac, M. Bio-energy use and low stabilization scenarios. The economics of low stabilization. Energy J. 2010, 31, 193-222.

60. Girod, B.; van Vuuren, D.P.; Hertwich, E.G. Global climate targets and future consumption level: An evaluation of the required GHG intensity. Environ. Res. Lett. 2013, 8, 014016.

61. UNFCCC, Copenhagen Accord: Proposal by the President, United Nations Framework Convention on Climate Change (UNFCCC). Available online: http://www.unfccc.int/ resource/docs/2009/cop15/eng/107.pdf (accessed on 19 August 2013).

62. United Nations Framework Convention on Climate Change (UNFCCC), Decision 1/CP.16: The Cancun Agreements: Outcome of the work of the Ad Hoc Working Group on Long-term Cooperative Action under the Convention. 2010. 
63. Rogelj, J.; Meinshausen, M.; Knutti, R. Emission pathways consistent with a $2{ }^{\circ} \mathrm{C}$ global temperature limit. Nat. Clim. Change 2011, 1, 413-418.

64. Goldthau, A. A public policy perspective on global energy security. Int. Stud. Perspect. 2012, 12, 65-84.

65. Abbott, M. Is the security of electricity supply a public good? Electr. J. 2001, 14, 31-33.

66. Kruyt, B.; van Vuuren, D.P.; de Vries, H.J.M.; Groenenberg, H. Indicators for energy security. Energy Policy 2009, 37, 2166-2181.

67. IEA. Energy Security and Climate Policy-Assessing Interactions; IEA/OECD: Paris, France, 2007.

68. CEC. Communication from the Commission: Making the Internal Energy Market Work COM/2012/0663; European Commission: Brussels, Belgium, 2012.

69. IMF. Energy Subsidy Reform; International Monetary Fund: Washington, DC, USA, 2013.

70. Frankfurt School UNEP Collaborating Centre for Climate and Sustainable Energy Finance. In Global Trends in Renewable Energy Investment 2012; Frankfurt School of Finance and Management: Frankfurt, Germany, 2012.

71. IEA. Energy Technology Perspectives 2012; International Energy Agency: Paris, France, 2012.

72. Nilsson, M.; Zamparutti, T.; Petersen, J.E.; Nykvist, B.; Rudberg, P.; McGuinn, J. Understanding policy coherence: analytical framework and examples of sector-environment policy interactions in the EU. Environ. Policy Gov. 2012, 22, 395-423.

73. World Bank. Global Tracking Framework; World Bank: Washington, DC, USA, 2013.

74. Bazilian, M.; Pielke, R. Making energy access meaningful. Issues Sci. Technol. 2013, Summer, 74-79. Available online: http://sciencepolicy.colorado.edu/admin/publication_files/2013.22.pdf (accessed on 1 September 2013).

(C) 2013 by the authors; licensee MDPI, Basel, Switzerland. This article is an open access article distributed under the terms and conditions of the Creative Commons Attribution license (http://creativecommons.org/licenses/by/3.0/). 